\title{
An In-Depth Analysis of the Causes of Road Accidents in Developing Countries: Case Study of Douala-Dschang Highway in Cameroon
}

\author{
Simon Armand Zogo Tsala1, Merlin Zacharie Ayissi2, Gerald Azeh³, Pierre Anicet Noah², \\ Fabien Betene Ebanda², Louis Max Ayina Ohandja ${ }^{4}$
}

${ }^{1}$ Department of Civil Engineering, Advanced Teachers Technical Training College of Ebolowa, University of Yaoundé I, Yaoundé, Cameroon

${ }^{2}$ Laboratory of Mechanics, University of Douala, Douala, Cameroon

${ }^{3}$ Ministry of Transport, Kupe Muanenguba Divisional Delegation, Bangem, Cameroon

${ }^{4}$ National Advanced School of Engineering Yaoundé, University of Yaoundé I, Yaoundé, Cameroon

Email: zogotsalas@yahoo.fr, zogotsalas@gmail.com

How to cite this paper: Zogo Tsala, S.A., Ayissi, M.Z., Azeh, G., Noah, P.A., Betene Ebanda, F. and Ayina Ohandja, L.M. (2021) An In-Depth Analysis of the Causes of Road Accidents in Developing Countries: Case Study of Douala-Dschang Highway in Cameroon. Journal of Transportation Technologies, 11, 455-470.

https://doi.org/10.4236/jtts.2021.113030

Received: April 27, 2021

Accepted: July 26, 2021

Published: July 29, 2021

Copyright $\odot 2021$ by author(s) and Scientific Research Publishing Inc. This work is licensed under the Creative Commons Attribution International License (CC BY 4.0).

http://creativecommons.org/licenses/by/4.0/

(c) (i) Open Access

\begin{abstract}
This paper is aimed at identifying the risk factors that mainly contribute to reckless driving and other related causes of road accidents along the Douala-Dschang highway of Cameroon. The research work started with the collection of accident reports for 2018 and 2019 from security officials in charge of road safety and the police stations of the different localities included in the sample of the study. Three hundred and eighty-two (382) road accidents reports were collected and analyzed using the 2020 version logit regression model of XLSTAT. From these analyses, it appears that, of the 382 accidents recorded during this period, six factors were identified and classified as follows: causes of accidents related to speed and carelessness, location of the accident, type of vehicle at fault, day the accident occurred, time of the accident and the age of drivers involved. These results could contribute to reduce the gravity of accidents along the Douala-Dschang highway and develop other policies in the program for road safety. In addition, this study can as much as possible equally contribute to reorienting road construction trends and development techniques in our environment.
\end{abstract}

\section{Keywords}

Road Safety, Traffic, Road Accidents, Douala-Dschang Highway, Logistic

Regression Model

\section{Introduction}

Reducing road accident injuries, disabilities and casualties is a global social and 
public health challenge. The World Health Organization (WHO) [1] [2] [3] estimates that the annual number of deads worldwide is over one million and is ever-increasing each year. The global report on road safety [4], launched by the WHO, highlights that the number of annual road accident-related deads has reached 1.35 million and that road accident-related injuries are now the leading killer cause of people aged from 5 to 29 years [4]. In fact, in all countries that have reached an advanced degree of technical development, a considerable mortality rate due to road accidents and the severity of the injuries they cause has been observed [5] [6].

Africa is not left out of this problem of traffic accidents. Every day, nearly a thousand people are killed and tens of thousands injured, not to mention the considerable economic losses they provoke [7]. Most African countries face significant gaps in awareness and capacity to promote road safety. As a result, investment in road safety is limited and the number of road crashes continues to grow rapidly in Africa. Cameroon in particular records an average of 16,583 road accidents each year, killing more than 1000 people, according to official figures and over 6000 according to WHO estimates [7] [8]. Road accidents involve very high costs which cannot be quantified only in terms of money, as costs may be permanent suffering for persons injured, loss of earning for the family members, and even death [8]. These figures can be increased with regards to certain peaks such as the 39 victims of Ndikinimeki on December 27, 2020 and most recently the 55 victims of the Santchou-Dschang cliff on January 27, 2021.

These aggregate figures do indicate the magnitude of the problem as a whole, but they do not identify sufficiently enough the nature of the problem in order to point to possible remedies. Similarly, the inadequacy of the results which might have been expected, given the immense efforts made throughout the world to collect as much data as possible on accidents, can be explained in part by the gaps left in certain fields, such as that of exposure to risk [9].

However, the accident is only the outcome of a chain of probabilities that characterize a situation that is not less purely complex. A classical representation consists of making correspondence to this situation in a space with several dimensions, divided into three subspaces namely of the road, the vehicle and the driver. The determination of the factors of road accidents within the framework of this paper will be based on this density [9]. Consequently, road safety has become an issue of international and national concern. The struggle to ensure road safety against accident needs stakeholders like the government, forces of law and order and local population [10].

Accidents and their casualties on roads are the results of a number of factors. Road users in Cameroon highways in general and those of the Douala-Dschang highway, in particular, are heterogeneous in nature, ranging from pedestrians, moto bikes, tourism cars, buses, trucks, and multi-axle commercial vehicles, etc. Besides the traffic movement of trucks transporting goods within this stretch of road, steadily increases during weekends due to the high movements of passengers by transport and personal vehicles to attend funeral services and celebra- 
tions in the west region. Increase in vehicle population with limited road space and its poor nature used by a large variety of vehicles has heightened the need and urgency for a well-thought-out policy on the issue of road safety.

In Cameroon, most road accidents occur along the Yaounde-Douala-BafoussamYaounde triangle. The Douala-Dschang highway which is our sample of the study is part of the National Road Number five (RN5) which is within the said triangle. The triangle is called the "death triangle" because it records over $46 \%$ [10], of the entire road accidents on the highways in Cameroon. Identifying the recklessness of drivers on road safety and related causes of accidents along the Douala-Dschang highway and the nature of road accidents is what the researcher of this paper is out for.

\section{Literature Review}

The review of literature relevant to road traffic accidents explains some basic concepts: types of accidents, position of vehicle and a consequence which imposes both tangible and intangible costs [4]. According to a joint World Health Organization and World Bank report [4], deaths from non-communicable diseases are expected to climb from 28.1 million a year in 1990 to 49.7 million by 2020, an increase in absolute numbers of $77 \%$. Among these diseases the road traffic accident which was ranked $9^{\text {th }}$ in 1998 was suggested to reach the $3^{\text {rd }}$ most sever killer in the world in 2020 [1] [2] [3]. The burden of road fatalities is increasing in the developing world where $86 \%$ of the world's road fatalities occur, with almost half of all fatalities in Asia [3]. According to WHO [11], road traffic accidents injuries and deaths reaches 6.560 which is $2.97 \%$ of total deaths in Cameroon, approximately one out of every 34 deaths. The age-adjusted death rate for road injuries is 35.06 per 100.000 of population, which ranks Cameroon number 28 in the world.

The traffic and road transport system as a whole is composed of three interactive parts which are the vehicles, the road environment and the road users. In the same way, any traffic situation is the result of the interaction among these three systems and in certain circumstances this interaction generates a critical situation or a crash. In general, the number of crashes is affected by three factors: the road environment, the condition of vehicles using the road system, the skillconcentration-physical state of road users [12]. In a number of research studies, notably those of Sabey [13], Kulhmann [14], Rothe, [15] and Gentile [16], human factors are the cause of more than $90 \%$ of accidents. Haddon [17] developed a matrix that identifies risk factors before the crash, during the crash and after the crash, in relation to the person, vehicle and environment. These points provide a context for this matrix in trauma prevention and management planning.

Although statistics do not allow us to determine with certainty the causes of road accidents, it is undeniable that, among the factors usually distinguished, the human factor remains paramount [18]. It may therefore be important to know what happens to the driver involved in an accident. In this context, studies have 
been carried out on the behavior of drivers [19] [20]. Also, other studies have focused on the geometric characteristics of the road that may contribute to congestion and accident production [21].

Although the literature on the subject is abundant, one should not expect to find rigorously established facts about driver behavior. There are reflections and observations, but no data that to justify. The subjects of studies are numerous but not enough in Africa, even less in Cameroon, although the phenomenon of accidents is prevalent in this country. It becomes imperative to conduct a causal study of road accidents in its entirety.

\section{Research Methodology}

After carrying out detailed comparative studies of the different types of research methodology [22], we proceeded with the presentation of the Douala-Dschang highway.

\subsection{Presentation of the Douala-Dschang Highway}

According to the Catalogue of the classification of roads in Cameroon [23], RN5 is a road that cuts across two regions (the Littoral and the West regions) and it measures approximately $258.6 \mathrm{~km}$ [23]. The sample starts from Douala central town and ends at Bafoussam central town with the following interceptive towns: Bikoko, Loum, Nkongsamba, Melong, Bafang and Bandjoun. An alternative path leads to Bafoussam using the stretch from Melong through Santchou and Dschang with a total distance of $237 \mathrm{~km}$ [23].

We are going to limit our study between Bikoko and the end of the Dschang cliff, passing through the following towns: Mbanga, Loum, Nkongsamba, Melong, Santchou and the Dschang cliff as presented in Table 1 and Figure 1 below. The choice of study of the stretch from Bikoko to the end of the cliff of Dschang measures $176 \mathrm{~km}$. The kilometric points of our study between Bikoko and the end of the Cliff is Pk25 and Pk201 respectively. This is the method of sectioning that is recommended in this type of study [24]. The selected portion of study was sectioned into four stretches as shown on Table 1 below.

Table 1. Presentation of the sample of study.

\begin{tabular}{|c|c|c|c|}
\hline Stretch & Description & Interceptive Towns and Villages & Distance \\
\hline Stretch 1 & Bikoko-Mbanga & $\begin{array}{c}\text { Bomono, Nkapa, Souza, } \\
\text { Malek, Kompina, Kombe, Muyuka. }\end{array}$ & $45 \mathrm{~km}$ \\
\hline Stretch 2 & Mbanga-Loum & Mombo, Njombe, Penja, & $33 \mathrm{~km}$ \\
\hline Stretch 3 & Loum-Melong & $\begin{array}{l}\text { Nlohe, Kolla, Mantem, Manjo, } \\
\text { Manengole, Nlonako, Nkongsamba, } \\
\text { Bare, Melong I, Melong II }\end{array}$ & $49.9 \mathrm{~km}$ \\
\hline Stretch 4 & $\begin{array}{l}\text { Melong-end of } \\
\text { Dschang Cliff }\end{array}$ & Lelem, Santchou, Fombap, Dschang Cliff & $49.1 \mathrm{~km}$ \\
\hline \multicolumn{3}{|r|}{ Total } & $177 \mathrm{~km}$ \\
\hline
\end{tabular}




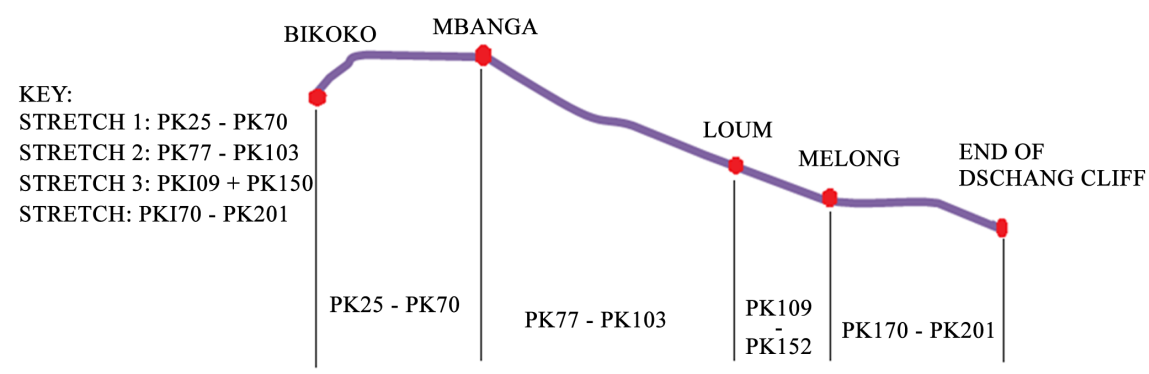

Figure 1. Stretch of study.

\subsection{Nature of Douala-Dschang Highway}

The dilapidation of the road and road signs as well are some factors that could lead to reckless driving and other causes of road accidents [24] [25]. Some of these could be potholes, narrow roads, sharp corners, and the absence of insufficiency and invisible road signs or critical points. Figure 2 presents some of the situations of the road. There are numerous spotted potholes along the entire stretch of road except the Dschang cliff. The potholes along stretch 1 are more severe. This situation of narrow roads is found mostly on the entire road of stretch 3 meanwhile sharp corners are mostly found along Nkongsamba-Melong and on the entire cliff of Dschang, on stretches 3 and 4 respectively. The absence, invisible or insufficient road signs are very crucial issues along the entire stretch.

\subsection{Data Collection and Method of Analysis}

\subsubsection{Data Collection}

The information on accident reports along the stretch of roads were obtained from the motorized road safety patrol of the "Gendarmerie" and the police services of the Menoua (Dschang, Santchou) and Moungo (Mbanga, Loum, Melong) divisions. A total of 177 and 171 accidents reports were collected for the year 2018 and 2019 respectively.

\subsubsection{Variables of the Study}

The independent variables (age of the driver at fault, day, time, kilometric point, type of vehicle at fault) and the dependent variable (nature of accident) had two categories namely 1 for fatal and 0 for non-fatal [26].

Six significant variables were statistically used. From Table 2 below, variables such as age of driver, day, time, location, type of vehicle and cause of accident had significant effects on the dependent variable. The measurements of the different variables are shown on the same table.

\subsubsection{Data Analyses Method}

The logistic regression model XLSTAT 2020 version was the method used for the description of the variables and modeling. According to Yin [26] and Agresti [27] Logistic Regression is the most preferred method where the independent variables are either categorical or a mixture of continuous and categorical variables. 


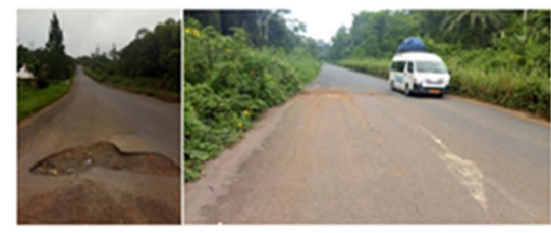

(a)

(b)

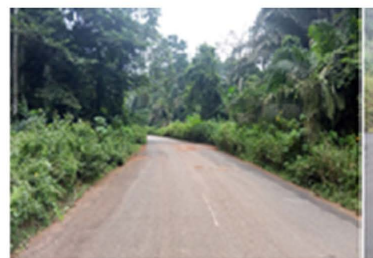

(e)

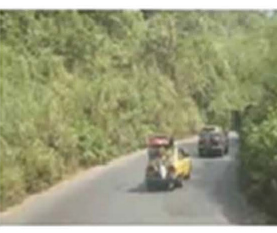

(c)

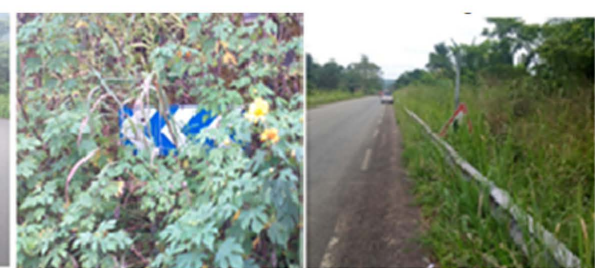

(g)

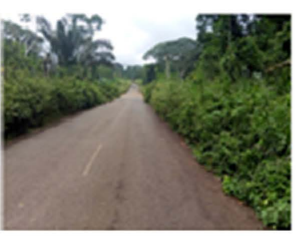

(d)

Figure 2. Some cases of the road situations along the stretch. (a) Potholes; (b) Dodging a pothole on a wrong lane; (c) Narrow road on Dschang cliff; (d) Narrow road on LoumMelong; (e) Sharp corner (Nkongsamba-Melong and Dschang cliff); (f) Invissible road signs; (g) Fasllen road signs.

Table 2. Variables and measurements

\begin{tabular}{cl}
\hline Age of driver & \multicolumn{1}{c}{19 to 70 years } \\
\hline Day & Weekly (from Monday to Friday) \\
Time & $\begin{array}{c}\text { Hours in four categories (6 am - } 12 \text { noon, } 12 \text { noon }-6 \mathrm{pm}, \\
6 \mathrm{pm}-12 \text { midnight and } 12 \text { midnight }-6 \mathrm{am})\end{array}$ \\
& Kilometric point/four group of categories: \\
Location & S1: PK25 - PK70 \\
& S2: PK77 + 800 - PK103 \\
& S3: PK109 + 300 - PK152 + 900 \\
& S4: PK170 + 500 - PK201 \\
Type of vehicle & Four groups of categories (bus, moto cycle, truck and VT) \\
Cause of accident & 1 for fatal and 0 for non-fatal
\end{tabular}

The principle of the logic regression model is to link the occurrence or nonoccurrence of an event to explanatory variables. XLSTAT can display the classification table used to calculate the percentage of well-classified observations for a given cut off point.

In this study, we code $y=1$ (non-fatal or corporal) and $y=0$ (fatal) [28]. The specific form of the logistic regression model used is:

$$
\ln \left[\frac{p}{1-p}\right]=\exp ^{\beta_{0}+\sum_{i=1}^{n} \beta_{i} \cdot x_{i}}=\exp ^{\beta_{0}} \cdot \exp ^{\sum_{i=1}^{n} \beta_{i} \cdot x_{i}}
$$

The fundamental equation for the logistic regression shows that when the value of an independent variable increases by one unit and all other values are held constant, the new probability ratio $\left(\frac{p}{1-p}\right)$ is given in Equation (2) as 
follows:

$$
\ln \left[\frac{p}{1-p}\right]=\exp ^{\beta_{0}+\sum_{i=1}^{n} \beta_{0}\left(x_{i}+1\right)}=\exp ^{\beta_{0}} \cdot \exp ^{\sum_{i=1}^{n} \beta_{i} \cdot x_{i}} \cdot \exp ^{\sum_{i=1}^{n} \beta_{i}}
$$

where:

$\beta_{0}=$ The constant model.

$\beta_{i}=$ The parameter estimates for the independent variables.

$x_{i}=$ The set of independent variables $(i=1,2, \cdots, n)$.

$p=$ The probability ranges from 0 to 1 .

$\ln \left(\frac{p}{1-p}\right)=$ The natural logarithm ranges from negative infinity to positive infinity.

Since the model contains explanatory terms, variables are specified in the model. For the $f^{\text {th }}$ observation, let $\pi$ be the estimated probability of the observed response. The three goodness-of-fit test criteria used for comparing different models for the same data in logistic procedures are: Roc curve and Wald Statistic test.

The odds ratio $(O R)$ is a ratio of two odds. Odds ratio was used to give us an idea of how strongly a given variable may be associated with the outcome of interest compared to other variables. For a probability of success $\pi$, the odds (likelihood) of success (in our case with risk factors) are defined as shown in Equation (3) below.

$$
O R=\frac{o d d s_{1}}{\text { odds }_{2}}=\frac{\pi_{1} /\left(1-\pi_{1}\right)}{\pi_{2} /\left(1-\pi_{2}\right)}
$$

An odd ratio of 1 indicates that the success or desired event under study is equally likely in both groups. An odd ratio greater than $>1$ indicates that the successful event is more likely to occur in the first group than in the second group and an odd ratio less than $<1$ indicates that the successful event is less likely in the first group [28].

\section{Results and Discussion}

The analyses of the data were realized in two phases: the descriptive statistics of the data and the prediction of the nature of accidents.

\subsection{Descriptive Statistics}

The number of observations stands at a sum of 382 accidents for the years 2018 and 2019. The outcome of the descriptive statistics of fitness is presented in the following subheadings.

\subsubsection{Frequency of Accident Victims and of Age of Driver at Fault}

The different measurement in the box plots of Figure 3 below show that about $20 \%$ of driver cause related accidents are provoked by drivers aged below 35 years and $80 \%$ of the drivers are aged above 35 years. The maximum age of driver cause of accident is 70 years meanwhile the average age is about 42 years. 

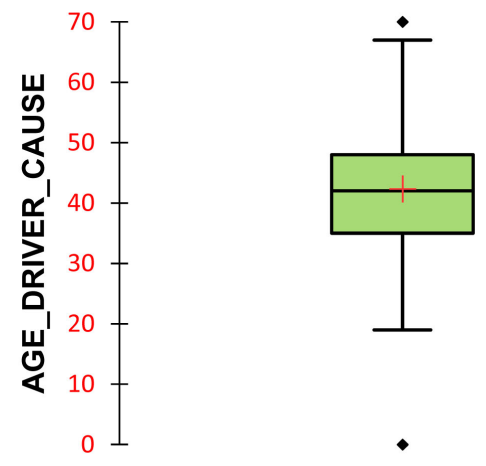

Figure 3. Age of driver cause.

\subsubsection{Day of Accident Frequency}

The frequency of accident per day is described as shown in Figure 4. Although Wednesday records 53 accidents, representing $15 \%$ of 379 of the net value of accidents, it was noticed that most of the accidental days within the week are Saturday with 80 accidents, Friday with 60 accidents and Sunday with 53 accidents representing $21 \%, 16 \%$ and $14 \%$ respectively.

\subsubsection{Time of Accidents Frequency}

The time frequency of accident was categorized into four groups namely, the accidents from 6 am to 12 noon, 1 pm $-6 \mathrm{pm}, 6 \mathrm{pm}$ to 12 midnight and from 12 midnight to $6 \mathrm{am}$. As shown on the pie chart Figure 5, it was noticed that out of 379 accidents that were used in the descriptive analyses, 134 accidents were recorded from 12 noon to $6 \mathrm{pm}$ and 144 from $6 \mathrm{pm}$ to 12 midnight representing $35 \%$ and $30 \%$ respectively. This indicates that the most accidental period in terms of time is from 12 noon to 12 midnight with a total of $65 \%$.

\subsubsection{Cause of Accident Frequency}

The causes were grouped into eight categories such as bad roads, car defects, drowsiness, excessive speed, imprudence/inattention, natural disaster, non-respect of road signs and poor overtaking. The bar chart of Figure 6 shows that so many reasons of accidents were attributed to human error with excessive speed being the highest cause with 130 accidents, inattention and imprudence with 115 accidents followed by 45 accidents attributed to non-respect of road sign representing $34.3 \%, 30.3 \%$ and $11.87 \%$ respectively.

Causes related to car defects recorded a total of 36 accidents representing 9.499\%. The records of the environmental factors were of 10 accidents for bad roads and 5 accidents for natural disaster representing $2.63 \%$ and $1.39 \%$ respectively should not be neglected. It should be noted that 322 out of 379 accidents were attributed to human factors (drowsiness, excessive speed, imprudence/inattention, non-respect of road signs and poor overtaking) making a total score of about $90 \%$.

\subsubsection{Type of Vehicles at Fault Frequency}

Vehicles involved in the accidents were categorized into four; Tourism Vehicles (VT), Trucks, Buses and Motorcycles. The pie chart of Figure 7 indicates that 


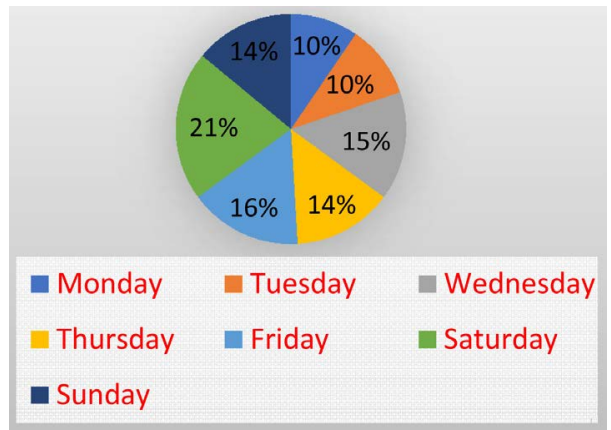

Figure 4. Day of accident frequency.

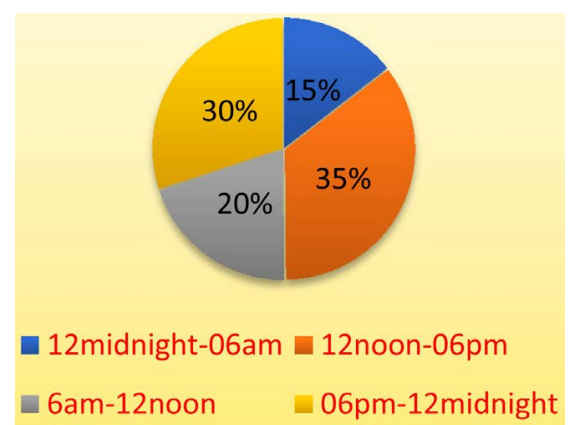

Figure 5. Time of accident frequency.

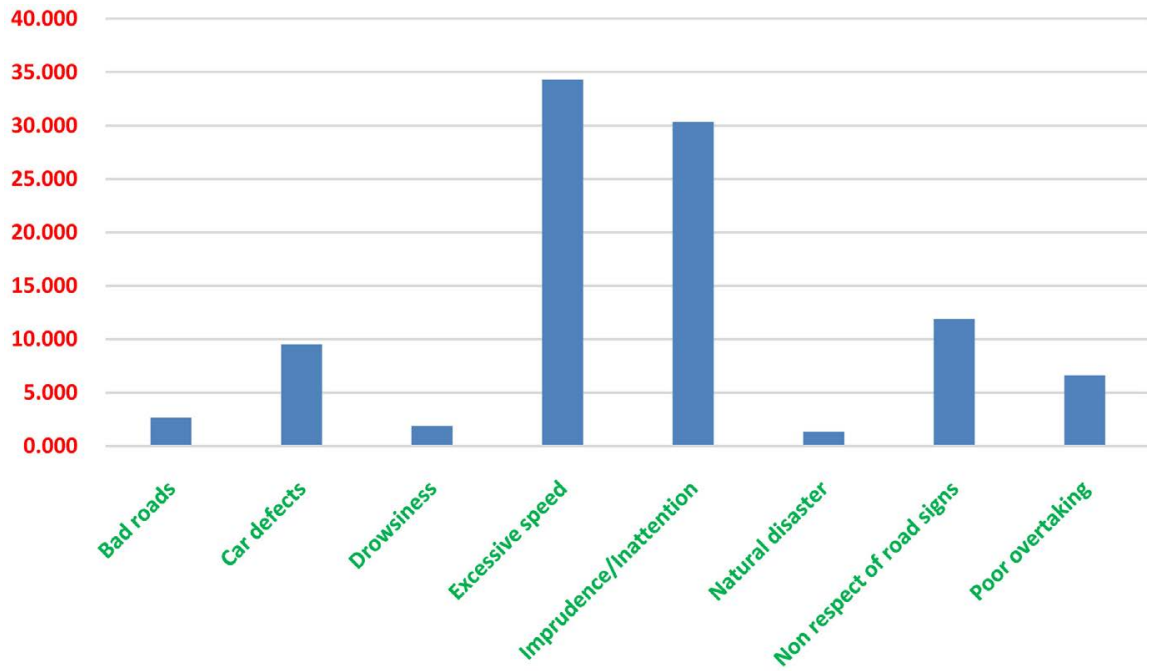

Figure 6. Cause of accident frequency.

$38 \%$ (140 accidents) of vehicles at fault were trucks; the tourism vehicles $31 \%$ (115 accidents) and $24 \%$ (86 accidents) vehicles at fault were buses. Surprisingly, $7 \%$ was also recorded for 24 accidents of motorcycles.

\subsubsection{Accident Location Frequency (Hot Spot)}

The study of accident hot spot was categorized into four sections and in 26 defined spontaneous kilometric points. The description in Figure 8 indicates that the highest hot spot of accident was in S3 and S4. S3 recorded 34 accidents at Melong, 15 at Manengole, 13 at Bare representing 8.97\%, 3.95\% and 3.43\% 


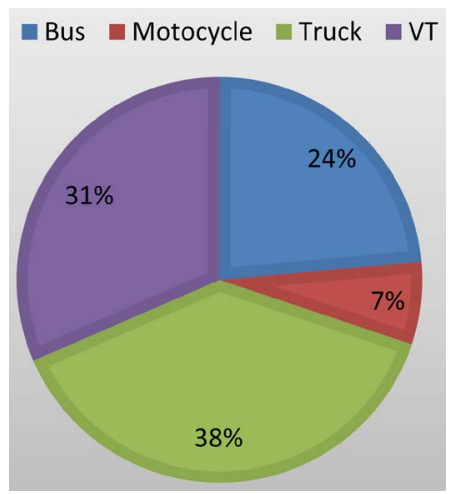

Figure 7. Type of vehicle at fault frequency.

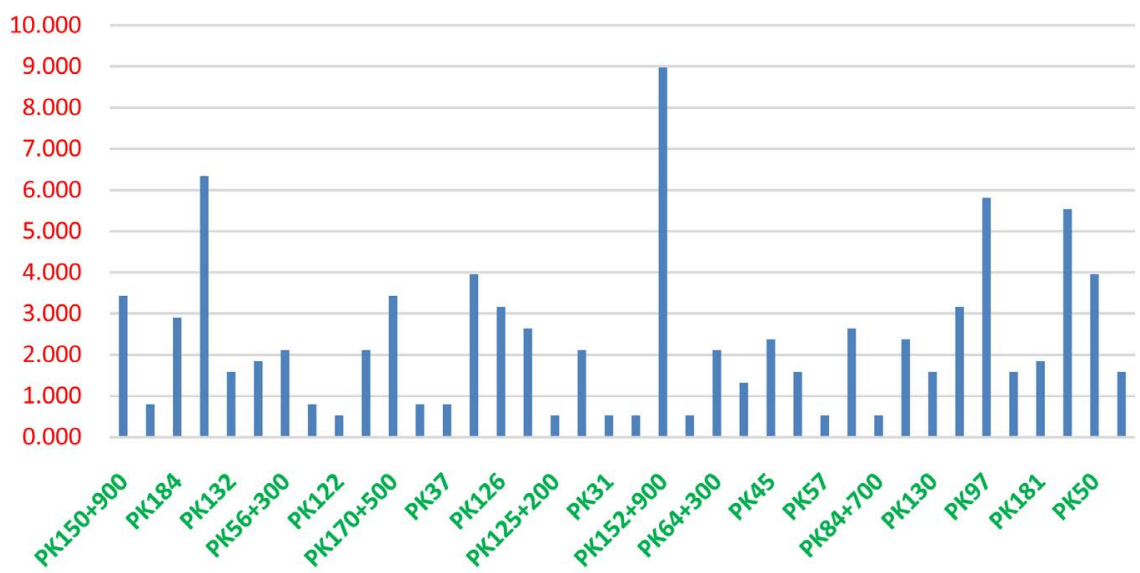

Figure 8. Accident location frequency.

respectively, meanwhile S4 recorded 24 accidents at Dschang Cliff, 13 at Lelem representing $6.33 \%$ and $3.43 \%$ respectively.

\subsection{Validation of the Model}

\section{- Null hypothesis test}

This test approves fitness of the model since the $\mathrm{Pr}>\mathrm{Khi}^{2}$ value is significantly less than the Wald value 1 . The validation test is presented on Table 3 below.

\section{- The ROC curve Test}

ROC curves in logistic regression are used for determining the best cut off value for predicting whether a new observation is a "failure" (0) or a "success" (1). Your observed outcome in logistic regression can only be 0 or 1 . The ROC Curve is a plot of values of the False Positive Rate (FPR) versus the True Positive Rate (TPR) for a specified cutoff value. The curve of our model fit is presented in Figure 9 below.

It was observed that the higher the ROC curve (the closer to line $y=1$ ) the better the fit. In fact, the area under the curve (AUC) can be used for this purpose. The closer AUC is to 1 (the maximum value) the better the fit. The ROC curve of model shows that the predictive power of the model is about $88.6 \%$ meaning about $88.6 \%$ of performance. Therefore, the model is of high 


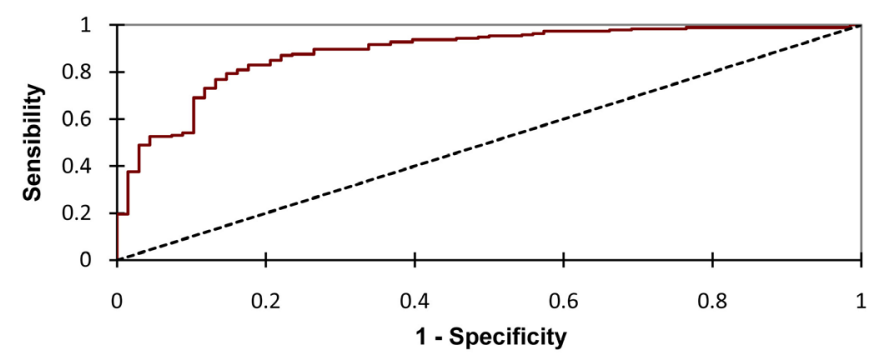

Figure 9. ROC curve $(\mathrm{AUC}=0.886)$.

Table 3. Hypothesis of the model.

\begin{tabular}{cccc}
\hline Statistic & DDL & $\mathrm{Khi}^{2}$ & $\mathrm{Pr}>\mathrm{Khi}^{2}$ \\
\hline$-\log$ (true resemblance) & 88 & 411.249 & $<0.0001$ \\
Wald & 88 & 42.177 & 1.000 \\
\hline
\end{tabular}

performance hence the fit for the prediction of road accident along the Douala-Dschang highway.

\subsubsection{The Logic Model}

From the analyses, the logic model with the significant variables is:

$$
\begin{aligned}
& \text { Pred (NATURE_ACCIDENT }) \\
& =1 /\left(1+\exp \left(-\left(-6.819 \times 10^{-2}-3.367 \times 10^{-2} \times\right. \text { AGE_DRIVER_CAUSE }\right.\right. \\
& + \text { DayFact }+ \text { TimeFact }+ \text { CauseFact }+ \text { TypeVehFact }+ \text { KPFact }+ \text { cte })))
\end{aligned}
$$

where:

- DayFact is a factor that takes the value corresponding to the day of accident;

- TimeFact is a factor that takes the value corresponding to the time of accident;

- CauseFact is a factor that takes the value corresponding to the cause of accident;

- TypeVeh Fact is a factor that takes the value corresponding to the type of vehicle;

- KPFact is a factor that takes the value corresponding to the Kilometric Point.

\subsubsection{Presentation of Model}

\section{- Cause of Accident}

CA-Excessive speed Vrs Natural disaster

$$
=\exp (-0.068+0.619) / \exp (-0.068-2.029)=14.105
$$

CA-Excessive speed Vrs car defects

$$
=\exp (-0.068+0.619) / \exp (-0.068+0.053)=2.558
$$

CA-Inattention / Imprudence Vrs Bad roads

$$
=\exp (-0.068+0.539) / \exp (-0.068-2.029)=13.016
$$

This shows that the impact of accidents due to reasons assigned for excessive 
speed is about 14 times higher than accidents due to natural disaster and about 2.6 times higher than accidents due to car defects. The impact of accidents due to Inattention/imprudence is about 13 times higher than that due to bad roads.

- Location of Accident ( $L A)$

$$
\begin{gathered}
\text { Pk152 + 900 Vrs Pk201 }=\exp (-0.068+3.520) / \exp (-0.068+2.987)=1.7 \\
\text { Pk152 +900 Vrs Pk122 }=\exp (-0.068+3.52) / \exp (-0.068+0.801)=13.45 \\
\text { Pk201Vrs Pk122 }=\exp (-0.68+2.987) / \exp (-0.068+0.801)=8.9
\end{gathered}
$$

In the case of accidents location, accidents at Pk152 are about 1.7 times higher than accidents at Pk201 and about 13.45 times more than accidents at Pk122 meanwhile accidents at $\mathrm{Pk} 201$ are about 8.9 times more than those at $\mathrm{Pk} 122$.

\section{- Type of Vehicle at Fault}

Type Veh-Truck Vrs Type Veh-Bus

$$
=\exp (-0.068+0.522) / \exp (-0.068+0.597)=0.927
$$

Type Veh-Truck Vrs Type Veh-Motocycle

$$
=\exp (-0.068+0.522) / \exp (-0.068-1.283)=6.007
$$

Type Veh-VT Vrs Type Veh-Bus

$$
=\exp (-0.06-0.562) / \exp (-0.068+0.597)=0.31
$$

In this case, trucks are about 0.927 times at fault than buses and about 6 times than motorcycles meanwhile tourism vehicles (VT) are at fault 0.31 times than buses.

\section{- DayCause}

$$
\begin{aligned}
& \text { Day-Saturday Vrs Day-Wednesday } \\
& =\exp (-0.068+0.575) / \exp (-0.068+1.039)=0.629 \\
& \text { Day-Saturday Vrs Monday } \\
& =\exp (-0.068+0.575) / \exp (-0.068+0.679)=0.901 \\
& \text { Day-Wednesday Vrs Day-Monday } \\
& =\exp (-0.068+1.039) / \exp (-0.068+0.679)=1.433
\end{aligned}
$$

On Saturdays and Thursdays, accidents occur about 0.629 times more than on Wednesdays and about 0.901 times more than on Mondays whereas it occurs 1.433 times more on Wednesdays than on Mondays.

\section{- Time Cause}

Time 12 noon-6 pm Vrs 6 pm-12 midnight

$=\exp (-0.068+0.868) / \exp (-0.068+0.765)=1.108$

Time 12 noon- 6 pm Vrs 6 am-12 noon

$$
=\exp (-0.068+0.868) / \exp (-0.068+0.424)=1.559
$$

Time 6 pm-12 midnight Vrs 6 am-12 noon

$$
=\exp (-0.068+0.765) / \exp (-0.068+0.424)=1.406
$$

Accidents between 12 noon $-6 \mathrm{pm}$ are about 1.108 times more than those between $6 \mathrm{pm}-12$ midnight and about 1.559 times more than those from $6 \mathrm{pm}$ 
-12 noon meanwhile, from $6 \mathrm{pm}-12$ midnight it is about 1.406 times more than accidents from 6 am - 12 noon.

\section{- Age of Driver Cause}

The Odd ratio was used to interpret the values age of driver at fault.

The odd ratio age of driver below 40 years being a factor for accident is shown as $\mathrm{e}^{-0.207}=0.813$. This means that accidents due to drivers' age above 40 years is $81 \%$ higher than drivers' age below 40 years old.

These results reflect the national and global trends in road accident causality studies and even their categorisation. These results are similar to those obtained by the psychologist Robert Ngueutsa [29] and BPA [30]. In its study on the explanation of road accidents related to causes and analysts in Cameroon, it notes that speeding, excessive speed; inattention/imprudence, time and day are accident related causes. Furthermore, the study conducted by the BPA states that lack of control and driver inattention is among the three predominant types of accidents on Swiss roads.

Moreover, on certain location or stretch, the level of risk will be higher than the general level of risk in other surrounding areas. Crashes will tend to be concentrated at these relatively high-risk locations. Locations that have an abnormally high number of crashes are described as crash concentrated, high hazard, hazardous, hot spot or black spot sites [25]. Therefore, it is important to conduct a study on such accident-prone sites if we want to limit the increase of road accidents. This study could develop mathematical models in order to determine the factors that affect accident rates for each black-spot. The methods for the analysis of black spots have been presented by Geurt and Wets [25] [31]. However, as we do not have a homogeneous road network, it will be difficult to compare our results with international results in terms of black spots. Also, the verbal processes used are subjective because of their non-uniformity.

\section{Conclusion}

This paper examined the risk factors involved in reckless driving and related causes of traffic accidents along the Douala-Dschang highway. The research work applied a quantitative methodology approach by using a logistic regression model of XLSTAT, 2020 version to predict the nature of accidents and to identify the various factors involved. The null hypothesis test and ROC curve test proves that the model is of high performance. The results obtained identified that most causes of road accidents along the Douala-Dschang highway are attributed to human behavior (drowsiness, excessive speed, imprudence/inattention, non-respect of road signs and poor overtaking) that gives a percentage of about $85 \%$. Excessive speed alone recorded $34.3 \%$ followed by imprudence/inattention with $30.3 \%$. The model identified that the hot zones are at Melong, Manengole and Bare representing $8.97 \%, 3.95 \%$ and $3.43 \%$ respectively. The groups of vehicles at fault most involved in accidents are trucks and tourism vehicles with $38 \%$ and $31 \%$ respectively. Saturdays and Fridays were identified as being the days during which most of the 
accidents occur with $21 \%$ and $16 \%$ respectively meanwhile the most accidental interval was from 12 noon -6 pm and 6 pm to midnight with $35 \%$ and $30 \%$ respectively.

\section{Acknowledgements}

The authors are thankful to Dr. ONOMO Cyrille (ESSEC, University of Douala), Simone OWONA (Ministry of communication, Yaounde, Cameroon) and Bide Ivo NGOME (College Catholique St Charles Borromee, Douala) for their critical review and valuable advice which improved the presentation of this paper. We also thank "Gendarmerie" and police officials and their units in the studied sample.

\section{Conflicts of Interest}

The authors declare no conflicts of interest regarding the publication of this paper.

\section{References}

[1] Organisation Mondiale de la Santé (OMS) (1999) Rapport sur la santé dans le monde. Organisation Mondiale de la Santé, Genève, 148 p.

[2] World Health Organization (WHO) (2015) Global Status Report on Road Safety. World Health Organization, Geneva, 340 p. https://www.who.int/health-topics/road-safety

[3] Transportation Research Board (2011) Achieving Traffic Safety Goals in the United States: Lessons from Other Nations. Special Report No. 300, Transportation Research Board, Washington DC, 77, 81. https://www.trb.org

[4] World Health Organization (WHO) (2018) Global Status Report on Road Safety: Summary. World Health Organization, Geneva, 20 p. http://apps.who.int/iris

[5] Organisation de coopération et de développement économiques (OCDE) (1992) Véhicules et réseaux routiers intelligents: Un billant des expérience pilotes. Organisation de coopération et de développement économiques, Paris, $191 \mathrm{p}$.

[6] Organisation de coopération et de développement économiques (OCDE) (1994) Gérer la congestion de la demande de trafic routier. Organisation de coopération et de développement économiques, Paris, 153 p.

[7] Groupe de la Banque Africaine de Développement (BAD) (2013) La Sécurité Routière en Afrique, Evaluation des progrès et enjeux du système de gestion de la sécurité routière. Département des transports et TIC. (WHO/NMH/NVI/18.20/Licence.CC BY-NC-SA) 3.0IGO, Belvédère, Tunis, 57 p. https://www.afdb.org

[8] Commission Economique pour l'Afrique (CEA), Organisation des Nations Unies (ONU), Communité Economique Européenne (CEE), Organisation des Nations Unies (ONU) (2018) Evaluation de la performance en matière de sécurité routière (EPSR) Cameroun, Nations Unies, New York et Genève, ECE/TRANS/NONE/2018/6, United Nation publication issued by Economic Commission for Europe, $71 \mathrm{p}$.

[9] Srour, D. (1969) Estimation statistique de la propension aux accidents. Accident Analysis \& Prevention, 1, 333-341. https://doi.org/10.1016/0001-4575(69)90079-7

[10] Ako, E. (2019) Impact of Road Safety and Accidents Prevention in Cameroon. Charisma University, Maaron Istg-Ac. https://doi.org/10.2139/ssrn.3404589 
[11] World Health Organization (WHO) (2017) World Malaria Report, Global Malaria Programme. World Health Organization, Geneva, 196 p. http://apps.who.int/iris

[12] Sayed, T. and Abdelwahab, W. (1998) Comparison of Fuzzy and Neural Classifiers for Road Accidents Analysis. Journal of Computing in Civil Engineering American Society of Civil Engineers, 12, 42-47. https://doi.org/10.1061/(ASCE)0887-3801(1998)12:1(42)

[13] Sabey, B. and Taylor, H. (1980) The Known Risks We Run. TRRL Report SR 567. Transport Research Laboratory, Crowthorne, Berkshire, Grande-Bretagne.

[14] Kuhlmann, A. (1993) Accident Prevention, A Complex Challenge for International Science, Alcohol Drugs and Traffic Safety. 63-80.

[15] Rothe, J.P. (1994) Beyond Traffic Safety. Transaction Publications, New Brunswick, $251 \mathrm{p}$.

[16] Gentile, F. (1994) La sécurité routière. Presses Universitaires de France, Paris, 127 p.

[17] Haddon Jr., W. (1972) A Logical Framework for Categorise Highway Safety Phenomena and Activity. Journal of Trauma, 12, 193-207.

https://doi.org/10.1097/00005373-197203000-00002

[18] Michaud, G. (1969) Un instrument du comportement des conducteurs d'automobiles, Organisation Nationale de Sécurité routière, Cahier d'étude No. 8. Accident Analysis \& Prevention, 1, 333-341.

[19] Tanaka, T., Fujikake, K., Yonekawa, T., Inagami, M., Kinoshita, F., Aoki, H. and Kanamori, H. (2018) Effect of Difference in Form of Driving, Support Agent to Driver's Acceptability. Journal of Transportation Technologies, 8, 194-208. https://doi.org/10.4236/jtts.2018.83011

[20] Sheykhfard, A., Haghighi, F.R., Soltaninejad, M. and Karji, A. (2020) Analyzing Drivers' Mental Patterns Using Q-Methodology. Journal of Transportation Technologies, 10, 169-181. https://doi.org/10.4236/jtts.2020.102011

[21] Savitha, B.G., Murthy, R.S., Jagadeesh, H.S., Sathish, H.S. and Sundararajan, T. (2017) Study on Geometric Factors Influencing Saturation Flow Rate at Signalized Intersections under Heterogeneous Traffic Conditions. Journal of Transportation Technologies, 7, 83-94. https://doi.org/10.4236/jtts.2017.71006

[22] Elkatawneh, H.H. (2016) Comparing Qualitative and Quantitative Approaches. SSRN Electronic Journal. https://doi.org/10.2139/ssrn.2742779

[23] Ministère des Travaux Publics (MINTP) (2011) Catalogue des Routes Classées du Cameroun, Centre de Traitement de l'Information Numérique (CTIN)/RGRC. Ministre des Travaux publics, Cameroun, $26 \mathrm{p}$.

[24] Service d'études techniques des routes et autoroutes (SETRA, 2009) Evaluation du risque routier par l'analyse de la lisibilité de la route. Rapport d'études, Ref: 0937w, 56 p. http://www.setra.developpement-durable.gouv.fr

[25] Geurts, K. and Wets, G. (2003) Black Spot Analysis Methods: Literature Review. Universitaire Campus GEBOUW D, Diepenbeek, 30 p.

[26] Yin, R. (1990) Case Study Research, Design and Methods. Vol. 5, Sage Publications, Inc., Thousand Oaks, $94 \mathrm{p}$.

[27] Agresti, A. (2007) An Introduction to Categorical Data Analysis. 2nd Edition, John Wiley \& Sons, Inc., Hoboken, 394 p. https://doi.org/10.1002/0470114754

[28] Awal, M. (2013) Identification of Risk Factors Involved in Road Accidents in Ghana. A Case Study of the Techiman Municipality. Thesis, Nkwame Nkrumah University, Faculty of Science and Technology.

[29] Robert, N. (2012) Croyances et comportements de sécurité des usagers et agents du 
trafic routier: Une étude des perceptions et de l'explication naïve des accidents de la route au Cameroun. PhD Thesis, University of Grenoble, 339 p.

[30] Bureau de prévision des accidents (BPA) (2014) UNIS report 2014. Level of safety and accidents in road traffic in 2013. Bfu, Bern.

[31] Sassanelli, D. and Ottomanelli, M. (2002) Planning Traffic Safety in Urban Transportation Networks: A Simulation-Based Evaluation Procedure. Proceedings of the 9 th Meeting of the EURO working Group on Transportation, Bari, 10-13 June 2002, 780-784. 